\title{
Research on Construction Mode of Practical Teaching Base Outside School
}

\author{
Dong Liu \\ Institute of Information Science and Technology South China Business College Guangdong \\ University of Foreign Studies, Guangdong, Guangzhou 510545, China.
}

78972493@163.com

\begin{abstract}
Keywords: Practice Teaching, Base Construction, Win-Win between School and Enterprise.
\end{abstract}
\begin{abstract}
In the course of construction of practical teaching base, aiming at cultivating high quality applied talents, the construction of "double reality" practical teaching base is carried out, which combines cognitive practice and professional practice organically. To promote the further construction of practical teaching base on the premise of win-win cooperation between school and enterprise.South China Business College Guangdong University of Foreign Studies takes "General Foundation, Fine Specialty, and emphasis on practice" as the mode of talent training, and devotes itself to cultivating practical and innovative talents with strong practical ability. The construction of practical teaching base plays an important role in carrying out practical teaching, improving teaching quality and enhancing students' innovative consciousness. Strengthening the construction and management of the practical teaching base, building the practical teaching base into a multi-functional, all-perspective, open practical interactive platform for the development of professional disciplines, so as to truly implement the practical teaching. In the construction of practical bases, no longer limited to the school, but to expand off-campus. Computer Science and Technology As an example, this paper discusses the related problems of practice teaching base construction, with a view to providing a reference for the construction of other professional college practice teaching bases.
\end{abstract}

\section{Introduction}

The guiding ideology of the construction of practical teaching base is to train applied talents as the goal, to take the market demand as the standard, to cultivate the practical ability as the main line, to form the student-oriented, knowledge and ability to develop and learn simultaneously. Create a multi-functional practical teaching base that promotes each other. [1] The college has built a group of stable and excellent multi-functional comprehensive practical teaching bases. Through careful guidance and standardized management, the practical teaching base has played a key role in the cultivation of talents with characteristics and the construction of discipline and specialty to the maximum extent.

The construction of practical teaching base should proceed from reality, start with the cultivation of applied talents, and construct a practical teaching system combining various forms and inside and outside the school. The practice teaching base can provide good environment for students, stimulate students' interest and potential. Students' innovative entrepreneurial training project, innovation cup competition and so on can be guided by the teachers of practice base. The construction of practical teaching base must have a certain scale, and should follow the construction principle of technology frontier and experiment, so that students can get practical operation training and improve their comprehensive quality in the real professional environment. 


\section{Problems Existing in Practice Teaching Base}

\subsection{Cognitive Level of Practical Teaching Base Construction is Limited.}

The school regards the practice base as simply a way for the cooperation of the school and the enterprise to provide the students with practical practice and does not realize the essential characteristics of the enterprise as the main body of the market in pursuing economic benefits. Enterprises cannot obtain economic benefits from the practice base, but also increase the input of manpower, material resources and generated resources, which leads to the lack of enthusiasm of enterprises to participate in the construction of the practice base.[2] Because the school practice is generally controlled in 8 weeks, the industry knowledge accumulated by the enterprise is difficult to impart to the intern in short term, which leads the enterprise to have a lot of anxiety in accepting students. Short practice period, long training time will take up the practice time, and students have doubts about their ability, it is difficult to let the students really deep into the enterprise environment.

\subsection{The Enthusiasm of the Practical Guidance Teacher is Not High.}

At present, the role of intern guidance teachers in school is relatively small, mainly some simple routine tasks: daily attendance, psychological counseling of intern students, preparation of practice documents and so on. Few mentors can go deep into the business with students and guide them in the field of professional work. On the one hand, some enterprises are only willing to cooperate with famous schools, famous majors, and the contents of cooperation are also very limited, and the positioning of enterprises themselves is biased, blindly emphasizing the role of economic subject, and neglecting the responsibility as the main body of society. [3] On the other hand, the school ignored the encouragement to the guidance teacher. Most of the practical guidance teachers were both the teachers of the theory course and the students. During the internship, it was difficult for the teacher to take both sides of the job.

\subsection{Problems in the Operation of Practical Teaching Bases.}

The teaching funds of the practical teaching base are insufficient, the arrangement of the practical teaching activities in the base is not organized, and the management system of the practical teaching plan, operation and examination is not perfect enough. Some companies desperately need people when they have more projects, with interns paying little or no payment. Some practice bases do not treat students' practice as routine work, and lack of concrete plan to guide students' practice, because of the change of leadership position, the practice cannot be carried out. During the practice period, students rely on the guidance and management of the enterprise personnel, so it is difficult to guarantee the effectiveness of the practice.

\subsection{The Effectiveness of the Internship is Not Satisfactory.}

The practice of students is mostly in the form of team practice, practice guidance teachers do not go to the enterprise to follow, it is difficult to judge the practice performance of each student, and most of them are based on the appraisal opinions given by the practice teaching base to judge the results. [4] The majority of practice-based appraisal opinions are formatted, written some appraisals or a seal. The lack of practical teaching experience, the lack of practical teaching experience, the lack of effective connection between practical teaching programs and enterprises, and the poor compatibility between professional courses and practical training make the practical effect greatly reduced.

\section{Exploration on the Construction Mode of Practical Teaching Base}

In the course of long-term teaching practice, combining the experimental training with the practice outside the school, combining the theory study with the practice application, exploring the construction model of the practice teaching base in various forms, putting forward the "double reality" based on the cooperation mode between the school and the enterprise.[5] Combining professional cognition practice and professional practice closely, in the course of personnel training mode and teaching system setting, the "double reality" practical teaching base model based on the cooperation of school and enterprise is established, and the scientific construction is carried out by relying on the practical training base outside school. Innovating the teaching system. 


\subsection{Professional Cognitive Practice.}

Freshmen have arranged professional cognitive internships, arranged for students to visit and study at the practice teaching base, and invited engineers from the practice teaching base to attend lectures for the students. This paper introduces the development trend of the industry and the mode of the enterprise operation, so that the students can establish a preliminary cognition of their own industry and lay the foundation for the graduation practice in the future.

\subsection{Professional Practice Based on Project.}

In the formulation of talent training program, the core professional courses are designed corresponding practical hours, and also with comprehensive practice. Professional practice through in-school experiments, in-school project training, off-campus project simulation to complete a variety of ways. As far as possible, the students' graduation practice projects should be arranged in order to make the students really contact with the professional practice and carry out the practice of the comprehensive practical ability of the majors before graduation.

\subsection{Innovating of the Idea of Cooperation between Schools and Enterprises.}

Practice teaching base at the beginning of the construction enthusiasm, but after a period of cooperation between the two sides tend to bland. Therefore, in the process of establishing the practice teaching base, we must consider what value students can create for the practice teaching base. [6] Both sides should make scientific management, establish perfect management system, provide system norm for carrying out practice activities, and promote the sustainable development of practice base. The basic teaching contents of the practical teaching base should be combined with the cultivation of students' innovative ability, and the long-term mechanism of cooperative education between school and enterprise should be explored, seeking win-win situation.

\subsection{Hardware and Software Construction.}

The practice teaching base undertakes the practice of students and promotes the development of practice teaching base through the establishment of special funds for the construction of practice base. [7] Build a scientific and reasonable comprehensive training platform to improve the versatility of practical teaching base. Improve the supporting hardware facilities, organizational management system and evaluation system, improve the effectiveness of student practice. [8].

\section{Conclusion}

The construction of off-campus practical teaching base is a long groping process, which needs the continuous investment and cooperation between the school and the enterprise. On the basis of further cooperation with the existing practical teaching base, the cooperation mechanism between the school and the enterprise should be perfected. Jointly improve students' practical ability. In order to improve the learning effect of students' practice teaching, a scientific and reasonable comprehensive training platform should be set up with the special funds for the construction of practice bases.

\section{Acknowledgments}

The Engineering Project of Teaching quality and Teaching Reform of undergraduate Universities in Guangdong Province in 2015 "South China Business College Guangdong University of Foreign Studies-Guangzhou Xiao Software Science and Technology Co., Ltd." (Guangdong Education High letter [2015] 133).

2016 South China Business College Guangdong University of Foreign Studies Project quality engineering practice teaching base in Hangzhou turtle Technology Co. Ltd. teaching base.

\section{References}

[1]. Ming Kenia. Exploration on the Construction of Off-campus practice Base for Marketing Specialty in Colleges and Universities [J]. Forum on Industry and Technology, 2015, 14(4):197-198. 
[2]. Sheen Chinua. To establish an external teaching base combining practice and employment [J]. Chinese higher education, 2011(19):43-44.

[3]. Form an association. Problems and Countermeasures in the Construction of National College students 'Extra-College practical Education Base [J]. College teaching in China, 2015(03):74-77.

[4]. Zhu Zhengwei, Yuan Liaoyang, Liu Dongguan. Exploration and practice of strengthening the Construction of practical Teaching Base [J]. College teaching in China, 2009(08):66-67.

[5]. Yang Changpeng. Construction of multiple modes of teaching practice base by close integration of industry, university and research [J]. Chinese higher education, 2007(11):46-48.

[6]. Hua Xuecheng. Research on the Development and Construction of practical Teaching Base of ideological and political Theory course in Colleges and Universities [J]. Jiangsu higher education, 2014(03):135-136.

[7]. Jiang Sheng Yuan, Gaol Xing, Sun Lidia, et al. Construction and Operation of Scientific and technological Innovation practice Base for College students [J]. Higher education in China,2007(18):44-46

[8]. Li Reyna, Yan Joshing. Study and practice on the Construction of practice Base of Law outside School [J]. Chinese university education,2008(05):79-81 